
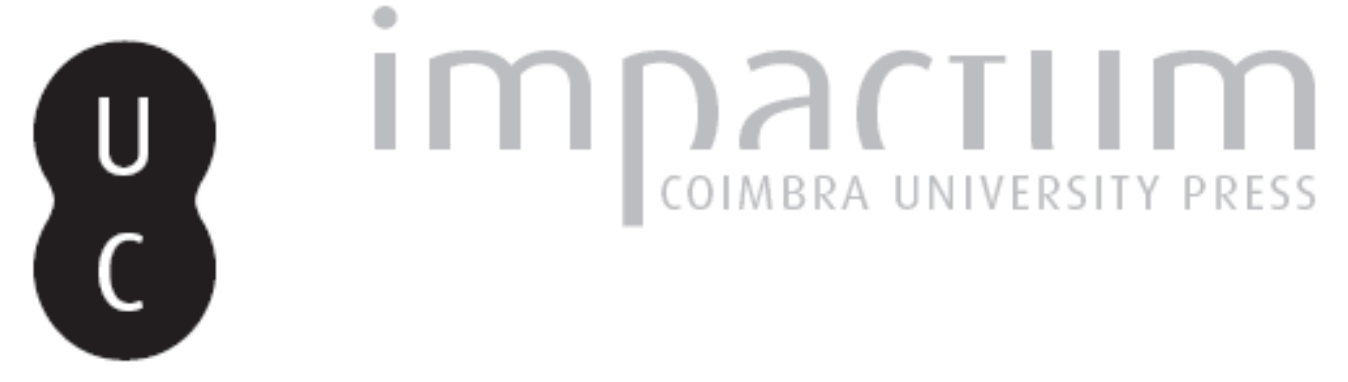

\title{
A cidade e as suas personagens em fim de século: quadro de emergência de uma cultura urbana de massas em Portugal
}

Autor(es): $\quad$ Peixinho, Ana Teresa; Dias, Luís Augusto Costa

Publicado por: Imprensa da Universidade de Coimbra

URL persistente:

URI:http://hdl.handle.net/10316.2/36941

DOI:

DOI:http://dx.doi.org/10.14195/2183-6019_1_6

Accessed : $\quad$ 26-Apr-2023 16:02:16

A navegação consulta e descarregamento dos títulos inseridos nas Bibliotecas Digitais UC Digitalis, UC Pombalina e UC Impactum, pressupõem a aceitação plena e sem reservas dos Termos e Condições de Uso destas Bibliotecas Digitais, disponíveis em https://digitalis.uc.pt/pt-pt/termos.

Conforme exposto nos referidos Termos e Condições de Uso, o descarregamento de títulos de acesso restrito requer uma licença válida de autorização devendo o utilizador aceder ao(s) documento(s) a partir de um endereço de IP da instituição detentora da supramencionada licença.

Ao utilizador é apenas permitido o descarregamento para uso pessoal, pelo que o emprego do(s) título(s) descarregado(s) para outro fim, designadamente comercial, carece de autorização do respetivo autor ou editor da obra.

Na medida em que todas as obras da UC Digitalis se encontram protegidas pelo Código do Direito de Autor e Direitos Conexos e demais legislação aplicável, toda a cópia, parcial ou total, deste documento, nos casos em que é legalmente admitida, deverá conter ou fazer-se acompanhar por este aviso.

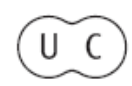


revista de comunicação,

jornalismo e espaço público

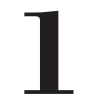

Periodicidade

Semestral

Imprensa da Universidade de Coimbra Coimbra University Press

\section{mediapolis}

os media e a construção

de personagens

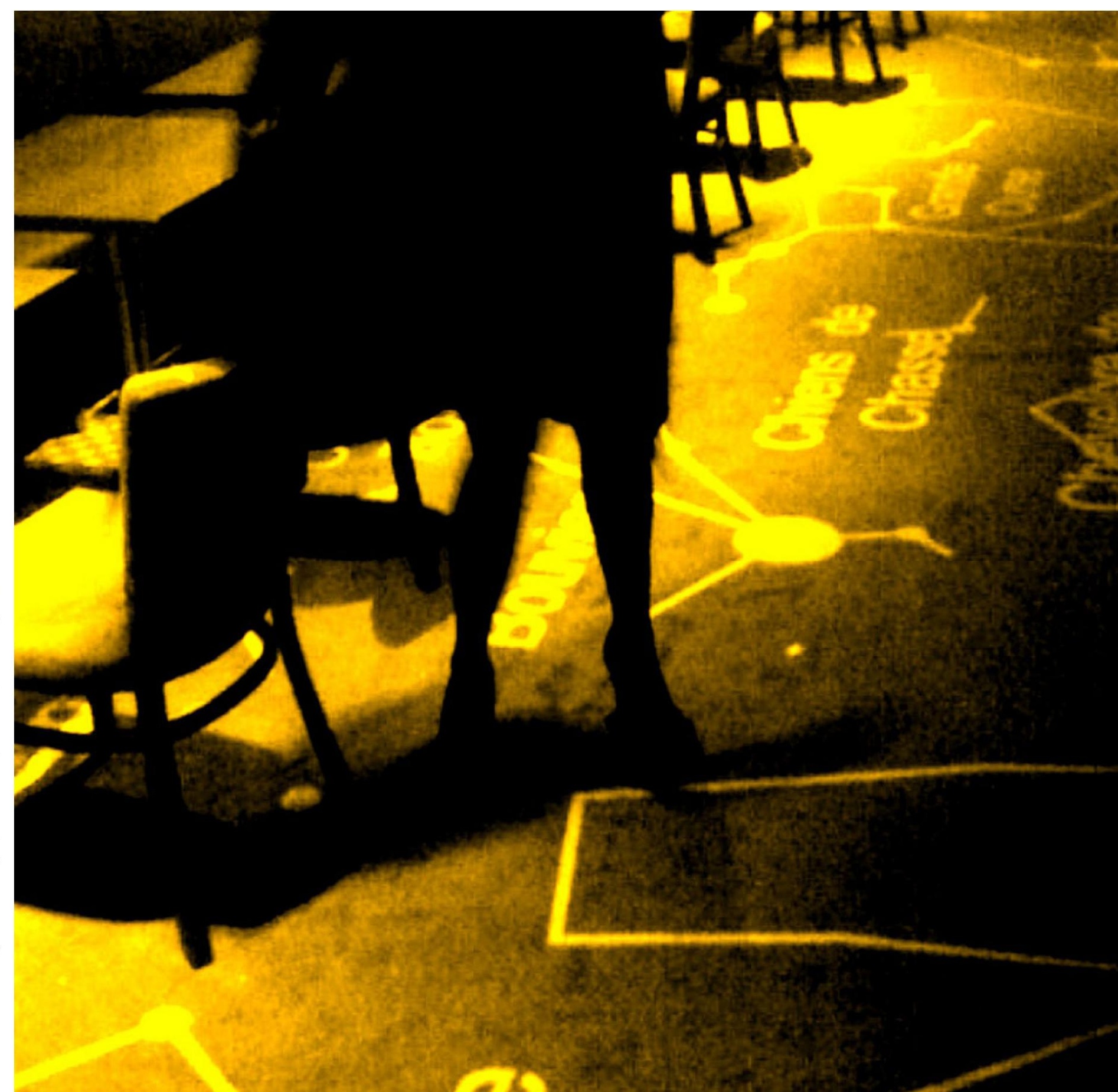



The city and its characters in the end of the 19th century: Framing the emergence of the urban mass culture in Portugal

\section{Resumo:}

Este artigo corresponde a uma etapa de um projeto de investigação mais amplo que pretende estudar a emergência da cultura de massas em Portugal no contexto da modernidade. Descreve-se, de um ponto de vista da história cultural, o contexto da civilização do impresso, que quadra entre o quartel final do séc. XIX e o do princípio do séc. XX, que foi o cenário típico da emergência de uma cultura de massas de matriz urbana envolvendo toda uma transformação social. A modernidade construiu, desde os seus fundamentos, este espetáculo feito de novos tipos sociais e profissionais, novos lugares urbanos de ócio e diversão, novas relações sociais e discursivas. Se, até ao dealbar da globalização, Portugal prolongou uma realidade estrutural essencialmente agrária a que corresponderam representações persistentemente rurais, constituindo fatores de resistência à modernidade que marcaram grande parte do nosso séc. Xx, a verdade é que, na transição para o século seguinte, podemos identificar um quadro cultural e social de efeitos multiplicadores de desenvolvimento que teve os centros urbanos como polo de importantes transformações.

Palavras-chave: Cidade, cultura de massas, personagens urbanas, imprensa.

\section{Abstract:}

This article represents a step in a broader research project that aims to study the emergence of the Portuguese mass culture in the context of modernity. We intend to describe the context of the "printed civilization" from a standpoint of cultural history. This period, that court between the final quarter of the nineteenth century and the early twentieth century, was the typical scenario of the emergence of a mass culture of urban matrix that involved an entire social transformation. Modernity, since its foundation, built this spectacle made of new social professionals, new urban places of leisure and fun, new social and discursive relations and types. If, during the industrial era and until the dawn of globalization, Portugal extended an essentially agrarian structural reality that corresponded persistently to rural representations (constituting factors of resistance to modernity that marked much of our twentieth century), the truth is that in the transition of the nineteenth century to the next, we can identify in the Portuguese society a cultural and social framework of multiplier effects of development that had urban centers as a hub of important changes.

Keywords: City, mass culture, urban characters, press.
* Abordagem experimental no âmbito de um projeto de investigação sobre "Modernidade e cultura de massas em Portugal (séculos XIX e XX)", numa parceria do Centro de Estudos Interdisciplinares do Século XX - Ceis20, da Univ. de Coimbra, com o Instituto de História Contemporânea da Univ. Nova de Lisboa. 


\section{Um novo espaço público urbano}

De regresso a Lisboa, aí por volta de 1887, numa encruzilhada de tempo retida pelo autor de Os Maias, "depois dum exílio de quase dez anos" na cosmopolita cidade de Paris para se refazer da sua anterior tragédia amorosa, Carlos Eduardo em vão procurava reconhecer velhos lugares, na companhia de João da Ega, sobretudo a mais simbólica das referências da capital. Onde outrora se estendera o Passeio Público da Baixa, murado de grades e solene no remanso de personagens lentas, rasgava-se agora um grande e movimentado boulevard:

- Ora aí tens tu essa Avenida!

Hem?... Já não é mau!

Não se tratava apenas, porém, da Avenida da Liberdade, que perdera o anterior "catitismo domingueiro" do velho parque gradeado; aliás, já as Avenidas Novas se projetavam então para o Campo Grande, quando a periferia da cidade tinha sido alargada no sentido de Belém e dos Olivais. Aliás, em breve, os transportes urbanos iriam aproximar o centro das margens urbanas: elétricos para Cais do Sodré e Algés em 1889, para o Campo Grande em 1906; comboios para Belém ainda em 1889. Eram também, em grande parte, outros os ocupantes da cidade, "toda uma geração nova" de gente que contribuía para desfigurar a "cidade velha” e, numa conversão geral, "arranjar-se à moderna" (Queirós, 1970: 690-703).

Ora, para o que à história cultural interessa, a cidade e as personagens, no cenário da fantasmagoria baudelairiana em fim de século que Walter Benjamin tão bem assinalou (Benjamin, 2011: 31 e ss.), são as ruas e os seus transeuntes - les rues e les flâneurs. Da dinâmica entre ambos, sob um cenário de espetáculo de que o meio urbano se tornava espaço apelativo, resultaram diversificados esquemas de circulação e formas sociais de apropriação da cultura, em tal momento sob o impulso e em torno dos objetos impressos, também estes sob uma nova dinâmica, por vezes mesmo com novos objetos.

Mais de uma década antes, já Eça de Queirós, na companhia de Ramalho Ortigão, “numa noite de verão, no
Passeio Público, em frente de duas chávenas de café" procurara, através das letras, "acordar tudo aquilo a berros" (Queirós, 2009: 159), compreendendo afinal que, ao abrir o último quartel do século, o espaço público começara a mudar com o despertar de novas camadas urbanas, essas que, num brevíssimo lapso revolucionário, o nosso escritor acreditou poderem sustentar uma Comuna em Lisboa: operários, pequenos comerciantes, trabalhadores de serviços (Queirós, 1983: 61). Um espaço público novo que Eça tão bem soube captar no final romanesco magistral de $O$ Crime do Padre Amaro, em que o Cónego Dias, o Conde de Ribamar e Amaro descem indolentes o Chiado, por onde ecoavam gritos dos ardinas, trazendo as novas da Comuna de Paris. Este cenário urbano, tumultuoso, construído de tipos novos e com uma dinâmica diferente, nunca passara despercebido ao escritor. Uns anos antes, em 1867, instalado na capital alentejana (não obstante um centro interior e de lento crescimento), o então jovem escritor olhava a cidade à distância e, vestindo com talento e mestria a pele de jornalista, comentava na coluna de 
uma "Correspondência do Reino" pela pena de um correspondente fingido:

\begin{abstract}
Agora vou por essas ruas, apinhadas de gente, indolentemente, estudando os tipos como um verdadeiro ocioso, rindo-me dos penteados femininos, vendo os $l i$ vros novos, ouvindo as dissertações políticas, a graça dolorosa e insípida dos nossos folhetinistas, mas olhando sobretudo para o sol, [...] como um verdadeiro meridional (Queirós, 1981: 540).
\end{abstract}

Ora, que dimensão e que relevância tinha então essa população urbana de final de século, com crescente acesso à cultura? Qual a dinâmica do seu despertar?

Se, ao longo da era industrial e até ao dealbar da globalização, Portugal prolongou uma realidade estrutural essencialmente agrária a que corresponderam representações persistentemente rurais, constituindo fatores de resistência à modernidade que marcaram grande parte do nosso século $X X$, a verdade é que, na transição do século XIX para o seguinte, podemos identificar na sociedade portuguesa um quadro cultural e social de efeitos multiplicadores de desenvolvimento que teve os centros urbanos como polo de importantes transformações. No sentido em que, para a nova história cultural, a população representa o corpo social sem o qual a cultura não pode integralmente ser pensada, é necessário partir de mobilidades sociais mais gerais - nomeadamente a deslocação migratória a partir dos meios rurais (para além de uma emigração expressiva, interessa aqui uma não menos importante deslocação interna para os principais centros urbanos). E, no seguimento de progressos materiais ao cabo do período "fontista", nomeadamente a interligação nacional ou, melhor, interurbana, pelas vias de comunicação telegráfica e ferroviária, encurtando o tempo e o espaço - avaliar que o nosso país assistiu no último quartel do século XIX, mais propriamente nas três últimas décadas, à primeira grande expansão dos meios urbanos da época contemporânea.

No interior do tecido urbano, outras mobilidades sociais participaram no arranque dos processos de industrialização e terciarização, já entre o último quartel de Oitocentos e primeiro quartel de Novecentos. Se muito destes fenómenos está ainda por conhecer em profundidade na sua dimensão económico-social, a expressão ainda menos abordada, porém significativa, como procuraremos mostrar aqui nos seus traços fundamentais, consistiu na emergência de uma cultura urbana de massas que, aliás, acompanhou sensivelmente a situação europeia da época (Dias, 2008; Kalifa, 2001). Trazendo uma vez mais o testemunho queirosiano, cuja obra, sobretudo a dos textos de imprensa, reflete e acompanha as grandes transformações societais do tempo, chamese à colação uma crónica enviada para a Gazeta de Notícias do Rio de Janeiro, porém escrita na capital francesa onde exercia funções diplomáticas: trata-se de um interessante texto de Ecos de Paris, datado de 1 de julho de 1894, intitulado "O Salon", que tem como mote um evento anual de grande projeção cultural - o salão de belas artes parisiense. No entanto, a argúcia e humor queirosianos conduzem mais longe que a referência a uma mera exposição, detendo-se o texto na verdadeira "peregrinação instrutiva" de 
que socialmente (leia-se pejorativamente) se revestia o evento, sobretudo porque permitiu ao cronista matéria de reflexão sobre questão mais funda que o aspeto artístico propriamente dito. Neste cenário, Eça apercebia-se da incapacidade inata do homem social na sua época - leia-se num final de século em ebulição - de pensar com a sua própria cabeça, de ajuizar livremente, independentemente dos ditames proferidos pelos líderes de opinião ou pelos jornais (aliás, também Stendhal, em textos publicados nas revistas inglesas, refletiu esta preocupação, perspetivando o jornal como um ecrã que opacificava a realidade, impedindo o contacto direto do cidadão com a arte e a literatura e conduzindo-o ao reduto das ideias feitas):

Como uma fila submissa de bons carneiros, todos estes milhares de seres pensantes, e únicos donos do seu pensamento, marchavam arrebanhadamente para aquelas obras que, na véspera, o Estudo Crítico, ou antes o Guia Crítico do "Salão", publicado pelo jornal, lhes indicava, ou melhor lhes impusera, como as únicas diante das quais deviam parar, e fazer "ah!" e sentir uma emoção, e depor um louvor (Queirós, 2002: 477).

A partir daqui, o autor alargouse em considerações, muitas delas ainda de grande atualidade, sobre o fracasso dos ideais revolucionários e da Democracia, pois que já no final do século XIX, o público (leia-se aqui o público urbano burguês) se comporta como o habitante de Damasco ou de Bagdad que não prescindia do seu “cádi” ou do seu "ulemá” para poder ter uma opinião que seguir; com uma diferença, imposta pelos tempos modernos: neste fim de século, nenhum homem civilizado que se queira respeitado pode prescindir da Arte ou da Literatura, pois elas representam a "sobrecasaca da inteligência", rápida e fugazmente consumidas nos jornais, afinal os grandes (de)formadores da opinião pública.

A cidade - de que Paris era, à época, o modelo - foi, no contexto geral da sociedade portuguesa da época a que nos reportamos, a grande "novidade" (Silva, 1996: 696) . Com mais precisão, do ponto de vista da história cultural, a cidade tornou-se cenário de valorização da rua e da sua frequentação quotidiana, de que o Naturalismo fez razoável inquérito literário à galeria de tipos e de ambientes sociais, desde Eça de Queirós a Abel Botelho, sem esquecer as crónicas citadinas que deram lastro à abordagem de costumes em que Fialho de Almeida se celebrizou, nem o magistral poema de Cesário "O Sentimento de Um Ocidental." Daí, a cidade tornou-se no centro de gravidade de novas e complexas práticas culturais e representações sociais variadas, segundo vivências que o novo espaço urbano então abriu, sob o signo de um conceito de cultura mais alargado.

O espaço público, para tomar de empréstimo à Sociologia um conceito muito generalizado que serve bem a nossa perspetiva, era então um espaço culto de natureza essencialmente urbana, compreendendo os indivíduos que, de alguma forma, participavam na vida pública e a determinavam numa esfera de interferência social e cultural mais alargada, isto é, para lá dos estreitos limites de uma burguesia culta e proprietária, típica do quadro romântico-liberal, mas integrando lentamente novos setores emergentes. 


\section{A cidade}

tornou-se no centro

de gravidade de

novas e complexas

práticas culturais

e representações

sociais variadas,

segundo vivências

que o novo espaço

urbano então abriu
Ora, a burguesia, em decisiva ascensão desde o século XVI, começara por modificar profundamente a esfera pública europeia desde meados do século XVIII. Público e privado passam a constituir-se como dois domínios distintos, embora mantendo relações e articulações, uma vez que o público só existe a partir de indivíduos que se assumam como tal na privacidade. ${ }^{1}$ A valorização da intimidade e o surgimento de um novo conceito de família, domínios separados da vida profissional, marcaram influências profundas ao nível dos processos de reprodução cultural. Antes, porém, do nascimento de uma esfera pública política, ela existiu no seio de um campo - o cultural, sobretudo o literário - que, embora ainda de forma incipiente,

1 Como explica João Pissarra Esteves: "Temos, assim, o público da modernidade projetado numa dupla relação com o privado: em contraposição e em estreita articulação. É esta ambivalência que estabelece o primeiro nível de mediação simbólica concretizada pelo público: a reunião das pessoas num público, o seu encontro num espaço comum [...] de discussão e de ação, começa por ser uma oportunidade de afirmação individual de cada um dos participantes, um espaço de desenvolvimento da interioridade e de afirmação subjetiva de cada um dos membros do público" (Esteves, 2003: 191). iniciou o seu processo de autonomização nesse século das Luzes. Não se tratava ainda de uma esfera distintamente burguesa, pois que abrangia a aristocracia urbana, frequentadora e dinamizadora dos salões e dos teatros. Na senda de Habermas, o termo público, na França do século XVII, era aplicado aos destinatários e consumidores de arte e literatura, tanto na corte, quanto nos salões aristocráticos e nos teatros. Filipe Carreira da Silva, numa leitura crítica da obra do filósofo contemporâneo, encontra uma síntese muito precisa para esta ideia quando afirma que "a esfera pública burguesa surgiu do encontro entre os herdeiros da sociedade aristocrática e humanista, em que se baseava a esfera pública literária, e a camada intelectual da burguesia, então em ascensão." (Silva, 2002: 17-18)

Se olharmos para uma das instituições que mais contribui para a formação e consolidação desta esfera pública - o salão - facilmente percebemos esta ideia. Os salões assumiram-se, desde cedo, como um espaço sociodiscursivo de nivelamento ou encontro de classes sociais distintas, em que a burguesia se infiltrava e convivia 
com a aristocracia. Os critérios de distinção social existentes fora do salão esbatiam-se através da conversação, modelo comunicativo igualitário, para James Melton, (2001). Segundo este estudioso, o salão tem algumas características essenciais da esfera pública do Iluminismo, nomeadamente o facto de a sua origem se prender com uma crescente autonomia relativamente ao mundo da corte, ser um espaço em que, apesar da preponderância da comunicação oral, a palavra escrita circulava e, finalmente, ser um espaço de nivelamento social em que se esbatia a rigidez e a formalidade da corte. ${ }^{2}$

Quer isto dizer, portanto, que o conceito de público moderno começa por ganhar contornos definidos no âmbito das artes e da literatura, publicitadas e discutidas nos salões, tribunas de legitimação das criações

2 "Eminence in the salon also undermined traditional conceptions of nobility based on birth by encouraging a more elastic behavioral definition. Eminence in the salon depended not on blood-lines but on the refinement and esprit one exhibited in conversation with others. Politeness and cultivation became qualities to which noble and bourgeois could aspire" (Melton, 2001: 195-225). artísticas ${ }^{3}$. Em Portugal, foi reconhecido o salão da Marquesa de Alorna foco de ebulição cultural, onde se debatiam as novas ideias políticas e também as novas correntes estéticas e literárias, frequentado por nomes como os de Bocage e Alexandre Herculano $^{4}$; em breve, na primeira metade do século XIX português, o salão ganhou crescente preponderância burguesa, de que pode, entre outros, dar-se o exemplo do salão de Maria Krus, animado por Almeida Garrett e onde participavam literatos e homens de negócios, políticos e funcionários; o próprio Grémio Literário, fundado no conturbado ano de 1846, pode verse como formalização pública dessa tendência. Naturalmente que, como explica Habermas, a par dos salões, existiram um conjunto de instituições variadas que em muito contribuíram

3 "El salón mantenía, por así decirlo, el monopolio de la primera publicación: um nuevo opus, incluído el musical, tenía que comenzar legitimándose ante esa tribuna." (Habermas, 2002: 72)

4 "Empossada no título e nos bens do Marquesado de Alorna, fez do seu salão um foco das novas ideias estéticas; a influência que exerceu, como "Staël portuguesa", ressalta do testemunho agradecido de Herculano" (Coelho, 1994). para a publicitação de ideias e para a circulação de produtos e de críticas culturais: cafés, ruelles, teatros. Entre outros, em que poderíamos acrescentar o aburguesamento das filarmónicas musicais que retiraram o monopólio dos salões cortesãos nos meados do Portugal de Oitocentos, são todos espaços urbanos, já que a cidade se configura como o polo aglutinador destes novos agrupamentos sociais, em que se começou a estabelecer "a paridade entre as pessoas cultivadas procedentes da sociedade aristocrática e as da intelectualidade burguesa" (Habermas, 2002: 70).

Estamos, portanto, perante o nascimento de um novo tipo de organização das elites cultas, em que "a divisão simbólica, fundada em motivos e convicções, [...] se sobrepõe $[\ldots]$ às tradicionais divisões religiosas, étnicas, económicas, etc." (Esteves, 2003: 194). Na esfera pública burguesa, numa perspetiva habermasiana que, como já se disse, não reúne consensos, a força da argumentação e os valores simbólicos sobrepunham-se a outros recursos de tipo material ou social; para além do mais, dinamiza discussões críticas, com base racional, 
sobre temas e assuntos até ao momento monopolizados pelo Estado e pela Igreja; um terceiro aspeto inerente a esta esfera pública burguesa, não obstante os estreitos limites de um modelo censitário em que, entrado o século XIX, a burguesia assentou o seu poder político (Habermas, 1997: 127), diz respeito ao carácter democrático da participação: ao menos em abstrato - e a configuração mais abstrata foi a construção oitocentista da ideia de cidadão ${ }^{5}$-, todos podiam participar, criticar, julgar bens acessíveis a todos.

O desenvolvimento de uma "república das letras" iluminista foi, para Habermas, o fundamento sobre o qual se estabeleceu uma exigência da república política. Desde cedo, portanto, na construção deste espaço público emergente, o impresso teve um papel angular, patente no valor das redes epistolares fulcrais nesta república das letras e que marcam muito bem a transformação de uma esfera pública literária em uma esfera pública política, através da reunião de pessoas privadas. Desta reunião nasceram públicos de debate que, em

5 No caso português, ver Dias (1990). última análise, deram lugar ao espaço público político. Assim, o ideal iluminista de um espaço público esteve ligado a um conjunto de fenómenos culturais no século XVIII, ampliados na centúria seguinte: desde o desenvolvimento de novos espaços públicos, como o parque, o museu e o café mas também à rápida expansão da indústria da imprensa, bem como à filosofia política liberal que moldou as grandes revoluções do século. O espaço público existiu na Europa das Luzes como uma rede discursiva, através da qual os indivíduos, abstraídos dos interesses privados, chegavam a consensos sobre questões públicas, através das discussões, das cartas, de livros ou de ensaios. Por isso, para Habermas, a sociedade civil, que cresceu em torno da cultura dos cafés e dos salões, resultou numa esfera pública literária que, em última análise, influenciou a esfera pública política.

À medida que, desde finais do século XVIII, se formou uma escrita especializada e aumentou o número de pessoas alfabetizadas, desenvolveu-se o gosto pelo espaço privado da vida doméstica, cada vez mais confinada à habitação da família nuclear restrita.
Foi neste espaço privatizado que foi possível experienciar uma nova forma de individualidade e de subjetividade e foi nessa experiência que, simultaneamente, o conceito de público passou a fazer sentido: o espaço público mantém-se público no sentido de que ele existe pela publicidade, o modo pelo qual as opiniões podem evoluir pela crítica e pelo debate para uma opinião pública, mesmo quando, para lá da literacia, o espaço público veio a alargar-se, já na segunda metade do século XIX, ante a concentração de massas nos meios urbanos.

\section{O espaço do publicado}

Por agora, esse espaço público é ainda essencialmente o espaço do publicado; a cultura, antes da afirmação de uma civilização da imagem e do som na passagem para o século $\mathrm{XX}$, era então predominantemente impressa, circulava e informava na forma de objetos impressos: do jornal e do livro estendeu-se ao folheto e ao cartaz publicitário, sem esquecer que estamos perante uma dinâmica de apropriações sociais da cultura (e da informação 
em geral) por via simultânea do ler, do ver e do ouvir (Dias, 2011). Esta civilização do impresso que finalmente nos ocupa, a partir da $2^{\text {a }}$ metade do século XIX - com a invenção das coleções literárias, nomeadamente em livros de bolso, a imediata e rápida afirmação da imprensa industrial, os jornais diários a baixo preço e de grande tiragem, dentre uma parafernália de folhetos, magazines e boletins de lazer cuja venda proliferava tanto em estabelecimentos livreiros e afins como em pontos comerciais fora do circuito habitual dos impressos -, surgiu concomitante com uma elevação paulatina dos níveis culturais da população urbana que contraria, afinal, a perspetiva de um atraso cultural português até há bem pouco dominante entre a nossa historiografia.

Pois, no último quartel do século XIX e numa tendência que se estendeu até ao primeiro quartel do século XX, o analfabetismo endógeno e persistente, sim, numa escala nacional (com índices próximos dos $80 \%$ dos indivíduos sem instrução, perto da percentagem da população rural) não se compagina com o crescimento da população residente no interior das principais cidades que, literacia à parte, possuía aptidões de leitura extensíveis a uma "massa semiletrada" de que a elite culta em vão pretendeu demarcar-se. Reconhecia-se, aliás, como fez Fialho de Almeida nas suas crónicas urbanas, a pressão daquilo a que chamou "cultura industrial" de objetos impressos generalizados e que Eça tão bem caricaturou na célebre carta-prefácio a Azulejos do Conde de Arnoso. ${ }^{6}$

Em breve panorama, indicadores mais precisos obrigam a mudar o ângulo de visão sobre o atraso cultural português. Por volta de 1880, antes mesmo do Maia e do Ega reconhecerem uma Lisboa transfigurada e a descentrar-se do fórum regenerador (figura 1), até então circunscrito pelas elites ao Rossio e Chiado, a percentagem da sua população urbana com acesso à cultura - isto é, todos os que, de alguma forma, sabiam ler e escrever (incluindo aqueles que as estatísticas, embora escassas, remetem para uma coluna intermédia dos que sabem ler, sem escrever) - ultrapassava os $50 \%$ dos indivíduos do sexo

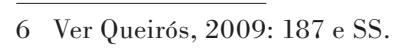

masculino residentes nos limites da cidade. Mas Lisboa não era um caso excecional, não obstante a capital ser a cidade megalómana que mais cresceu durante todo este período: a população com apetências de leitura na Coimbra escolar (com 56\%) e no Porto culto de fim-de-século (com $55 \%$ ) era mesmo superior à dos lisboetas (que rondavam os 54\%). E esta era a situação nas principais cidades portuguesas de um eixo litoral que começava em Viana do Castelo e terminava em Lisboa, desfasado do interior e sul do país, aí escassamente alfabetizado mesmo entre os citadinos (por exemplo, Castelo Branco com $28 \%$, Beja com $30 \%$ e Faro com $25 \%$ dos seus habitantes de alguma forma instruídos) ${ }^{7}$.

Tais indicadores permitem, então, explicar de forma decisiva a curva ascendente nas extraordinárias tiragens das publicações periódicas, sobretudo dos títulos diários, sabendo que os jornais finisseculares concorriam entre si nos grandes centros urbanos. Antes de Carlos da Maia regressar da Europa

7 Dados referentes ao início do último quartel do século XIX in Anuário Estatístico (1884). 
Figura 1

Uma Lisboa transfigurada e a descentrar-se

do fórum regenerador, até então circunscrito

pelas elites ao Rossio e Chiado.

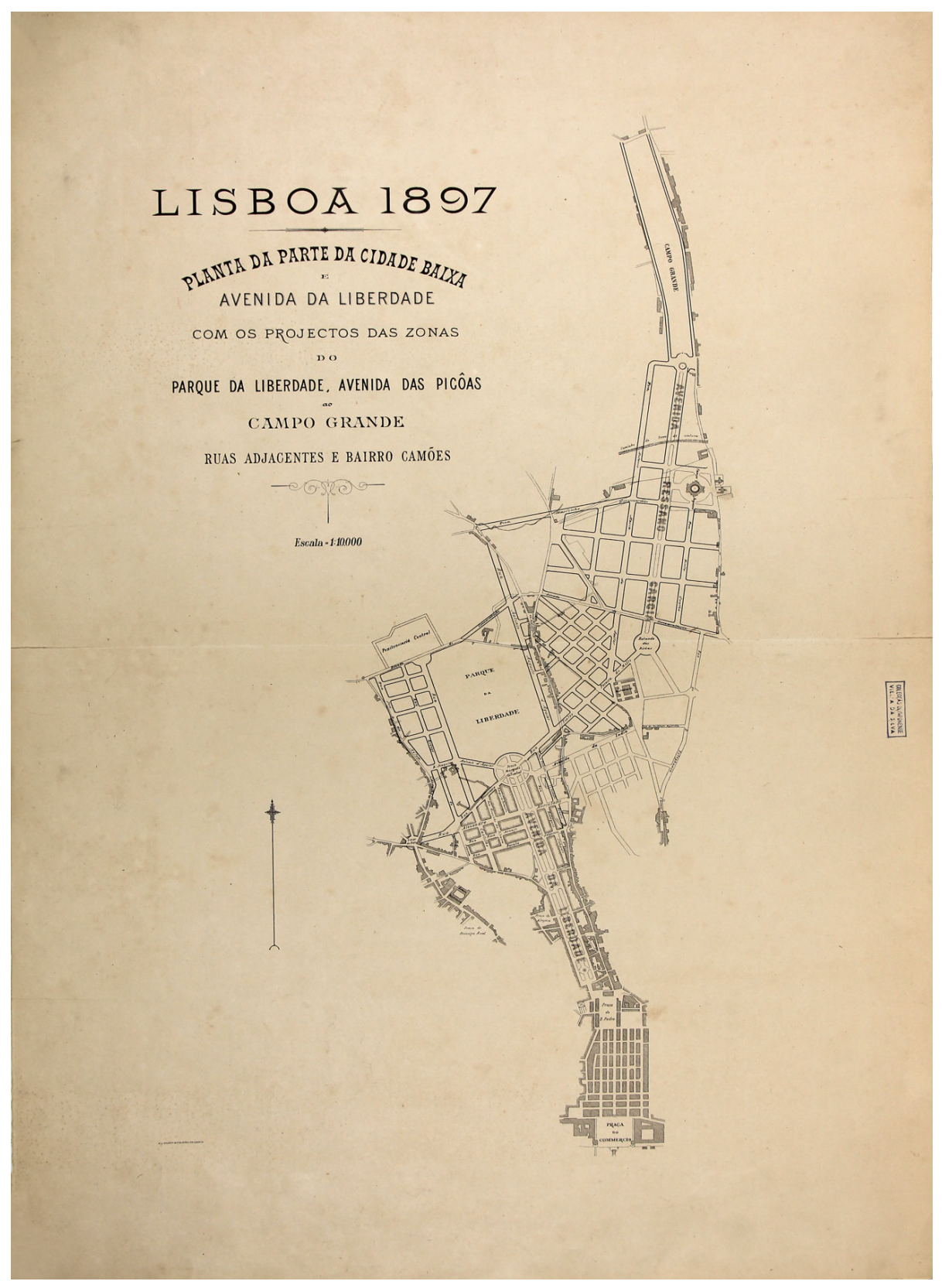


(acreditando ele que, essa, sim, era culta, numa apreciação vista do alto das elites), a população residente em Lisboa, com cerca de 300 mil habitantes, tinha disponíveis tiragens diárias de 50 mil exemplares de jornais (Cunha, 1941: 10 n.), 17 mil dos quais por conta do pioneiro Diário de Notícias (Miranda, 2002: 128) - isto é, cerca de um exemplar para 6 habitantes da capital. Até final do século XIX, quando o Diário de Notícias tirava cerca de 30 mil exemplares diários, já um novo vespertino lisboeta ultrapassava tais tiragens (Salgado, 1894: 60). Trata-se de $O$ Século que, em breve, veio a construir um verdadeiro (e o primeiro) império mediático em Portugal e, antes de 1910, atingia a tiragem média de 85 mil exemplares diários ${ }^{8}$ - quase o dobro em dias de acontecimentos relevantes, segundo memória de Brandão (1998: 142). Nessa altura, os lisboetas pouco mais eram que 400 mil residentes urbanos, havendo uma proporção de um jornal para 4 habitantes da capital. Naturalmente, as tiragens eram também expedidas para fora do grande

8 Segundo uma publicação do "império" de O Século, a Ilustração Portuguesa (1908, jul. 13). centro urbano, pelo menos com 1/4 dos exemplares destinados a pequenas e próximas cidades e vilas; no caso de O Século e do Diário de Notícias, deve contar-se com uma circulação para outras cidades do país - a verdade, não obstante, é que o índice de consumo direto de impressos nos grandes núcleos urbanos foi nessa época considerável.

Por esta altura, quando vamos já conhecendo os níveis dos lazeres populares através de atividades de cultura e recreio a que só era possível aceder com um mínimo de instrução (Figueiredo, 2011), também os periódicos dos meios laborais conheciam ampla circulação, como foi o exemplo do semanário Voz do Operário, editado pela coletividade homónima, que tirava 50 mil exemplares por número em $1908{ }^{9}$. Nas dinâmicas culturais da transição de século, a leitura popular, como prática de rua, foi, aliás, belissimamente iconizada pelo fotógrafo Joshua Benoliel, na capa da Ilustração Portuguesa de 13 de junho de 1908: com o título sugestivo "À esquina”, a "chapa" do nosso fotógrafo surpreendia um moço de fretes, de gancho ao

9 Exemplo dado pela Ilustração Portuguesa. (id.). ombro e farda de serviço ${ }^{10}$, lendo um jornal numa esquina da cidade. E à leitura popular, identificando novas franjas de um espaço público socialmente alargado, devemos ainda acrescentar a leitura feminina, cujos ganhos através da instrução atravessaram o último quarto de século de Oitocentos (Gomes, 1996: 33 e seg.), dando finalmente lugar à primeira e notável geração de "feministas" dos princípios de Novecentos (Lousada, 2012).

Ora, a imprensa de larga difusão construiu estratégias e criou dispositivos de afirmação, fidelização e ampliação de públicos que tiraram partido de uma encenação do espaço urbano, reforçando a sua presença nesse cenário de espetáculo. Antes de todos, o Diário de Notícias fez crescer as suas tiragens com a introdução de quiosques de rua espalhados pelo espaço urbano, mas também com o recurso aos ardinas que apregoavam as notícias a céu aberto e cujo número não parou de aumentar até ao

10 O uso de farda pelos "moços de fretes" (figura 2) fora determinado numa então recente postura municipal, demonstrativa da integração das personagens numa paisagem urbana que se pretendia moderna. 


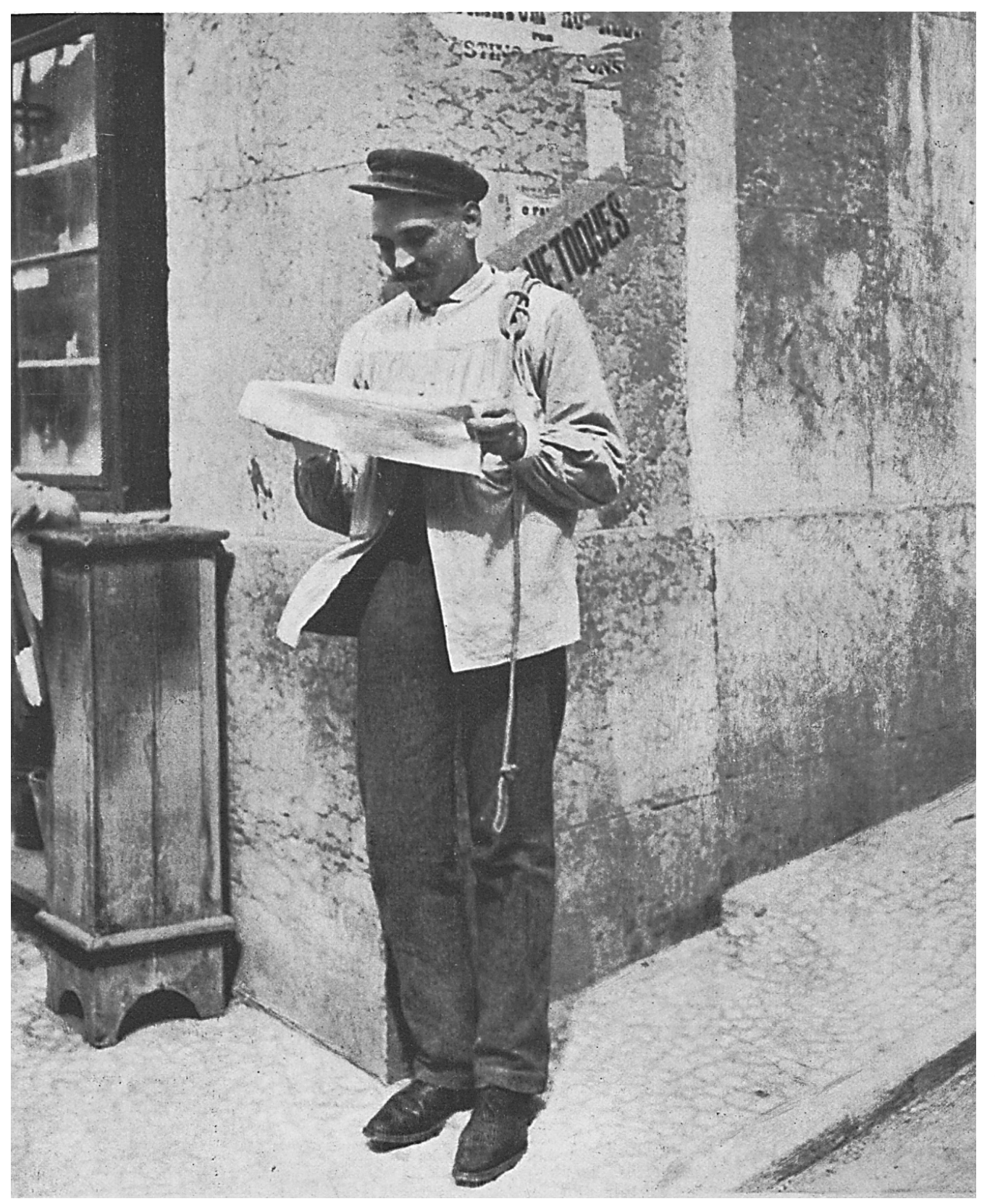


final do século XIX: em 1891, estavam registados no Governo Civil de Lisboa quase 10 mil ardinas(Cunha, 1941: 36-40). Já por essa altura, O Século expandia-se com ramificações pelos principais bairros da capital, através da criação de sucursais em lojas que chegaram a ser 17 na cidade de Lisboa em 1911, altura em que recorreu igualmente aos quiosques para se localizar em praças e jardins; na mesma época, estendia essas sucursais a vilas próximas em crescimento, por exemplo em Almada e na Amadora (nesta, situada no "centro comercial" junto à sede dos "Recreios"). A completar esse espaço mediatizado, os jornais possuíam em geral, espalhados pela cidade, pontos de afixação das notícias que eram lugares de difusão privilegiados, segundo um jornalista lisboeta: "Por toda a parte, onde os jornais têm "placards", o povo estaciona, em massa, comentando os acontecimentos"11; aliás, conforme afirmava um jornal portuense, antes de chegarem aos pontos de venda, ainda antes de apregoadas pelas ruas, as notícias

11 O País (1908, ag. 21). eram publicadas "primeiro num placard que fizemos afixar nos lugares do costume"12.

Não se trata, porém, de um processo isolado da dinâmica urbana em geral: esse espaço mediatizado correspondia, integrando-se nele, a um cenário de espetáculo nas principais cidades que começava nas fachadas dos prédios, por vezes com térreas arcadas de passagem, e terminava nos quiosques de café ao ar livre, em percursos que os transeuntes faziam sob o colorido e as formas dos toldos, dos avançados metálicos, das placas publicitários, dos cartazes comerciais ou de espetáculos; mas também ao ritmo dos novos aparelhos de reprodução sonora, vulgares no princípio de novecentos entre comerciantes de porta aberta que chamavam a atenção do público com essa música de rés-dochão ${ }^{13}$. A cidade multiplicava então, aliás, uma diversidade de acontecimentos artísticos, alguns de amadores em plena rua, a céu aberto... mesmo os mais inusitados e capazes

12 O Comércio do Porto (1908, out. 5).

13 Informação (e expressão sublinhada) que devemos e agradeçemos ao meu colega $\mathrm{Ma}-$ noel Denis Silva (IHC/UNL).

\section{A imprensa de larga difusão} construiu estratégias e criou dispositivos de afirmação, fidelização e ampliação de públicos que tiraram partido de uma encenação do espaço urbano 
de encher, em poucas horas, um largo, uma praça com milhares de espectadores.

A civilização do impresso, que quadra entre o quartel final do século XIX e o do princípio do século XX, foi, pois, o cenário típico da emergência de uma cultura de massas de matriz urbana que envolveu toda uma transformação social: a modernidade construiu, desde os seus fundamentos, este espetáculo. A imprensa, cujo ambiente apenas aflorámos, foi disso um exemplo, mesmo na sua narratividade, nos instrumentos de escrita (motivos, técnicas, recursos) que o jornalismo moderno autonomizou sob a égide do momento, do acontecimento. Para efeitos políticos ou quaisquer outros efeitos mais comezinhos na dinâmica desse cenário urbano, a espetacularização da notícia esteve presente nessa matriz de massas: a "invenção" do acontecimento, incluído o sentido em que toda a literatura é invenção, não descurou o efeito metafórico, a amplificação, o exagero, o insólito; mesmo no mais fugaz, efémero, quotidiano acontecimento, a intriga, o crime, o facto escabroso ou simplesmente inusitado dão matéria de "reportage" ou de "interview" (então, assim mesmo, ainda sem tradução, os grandes géneros do moderno jornalismo nascente), com uma vivacidade acrescentada ao facto, um poder de sugestão e de emoção com que os novos "reporters" enfatizavam o caso. Afinal de contas, afirmava um jornalista da época, tal imprensa guiava-se "pela necessidade incessantemente renascida de procurar a variedade, de achar novidades" conforme "o paladar do leitor [...] que absorve especialmente toda a curiosidade moderna" ${ }^{14}$.

Porém, o "paladar" das elites cultas, nesse tempo que era já de crise do Naturalismo, acentuava uma tendência do imaginário para o ruralismo, o bucolismo, a tradição, a ancestralidade na literatura, como na pintura, na fotografia, nas artes em geral. Aliás, a elite culta na transição de século trouxe, com conceitos e práticas, a ideia de fruição do campo na cidade, com a criação e ampliação de parques e, no limite, com esse ritual tornado simbólico da plantação da árvore com data marcada no calendário (republicano).

14 Trecho de uma crónica na Ilustração Portuguesa (13 jul. 1908).
Com a exceção de Cesário Verde e da sua poesia de ambiente urbano e, também por isso, percursor de uma modernidade estética, foi necessário esperar pela vanguarda modernista para assistir a um assomo citadino que teve em António Ferro, o jornalista capaz de experienciar a cidade, os seus ritmos, as suas emoções, as suas personagens. Nessa altura, porém, o processo de crescimento de uma cultura de massas de matriz urbana, fruto de uma ampliação do espaço público por via de importantes transformações no corpo social no último quartel do século XIX e primeiro quartel do século XX, sofreu um abrandamento considerável durante o regime Republicano e um retrocesso decisivo durante o regime do Estado Novo que suspenderam, já para lá de meados desse último século, nova e decisiva explosão da cultura de massas. 


\section{Bibliografia:}

Anuário Estatístico, 1864-1925.

Benjamin, W. (2011). Paris, Capitale $d u X I X^{e}$ Siècle. Paris : Alia.

BRANDÃO, R. (1998). Memórias I. Ed. J. C. Seabra Pereira. Lisboa: Relógio d'Água Edit.; [1ª ed., Porto: Renascença Portuguesa, 1919].

CUNHA, A. da (1914). O Diário de Notícias. A Sua Fundação e os Seus Fundadores. Lisboa: Tip. Universal.

DIAS, L. A. C. (2011). "A entrada de Portugal na era mediática: imprensa e cultura urbana de massas na transição do século XIX para o século XX". In: Why Culture? Coimbra International Congress. Coimbra

- (2011). "Constituição de uma cultura de massas na protohistória dos modernos intelectuais". In: Tradição e Modernidade no Mundo Iberoamericano. Coimbra [atas em prep.]. - (2007). "O papel do impresso. A imprensa e a transformação do espaço público em Portugal (último quartel do século XIX - primeiro quartel do século XX"). In: Estudos do Século $X X, 7$. Coimbra : Imp. da Universidade, 307-317.
- (1990). "Uma doutrinação liberal da "opinião pública" como modelo de intervenção cívica". In: GARRETT, A.. Doutrinação Liberal. Lisboa: Publ. Alfa.

ESTEVES, J. P. (2003). O Espaço Público e a Democracia. Comunicação, processos de sentido e identidades sociais. Lisboa: Colibri.

GOMES, J. F. (1996). "Escolas normais para habilitação dos professores primários". In: Estudos para a História da Educação no Século $X I X .2^{a}$ ed. Lisboa: Inst. Inovação Educacional.

FIGUEIREDO, C. (2011). Arte, Redenção e Transformação. A Experiência da Sociedade Teatro Livre (19021908). Lisboa: F.C.S.H./Univ. Nova Lisboa [dissert. Mestrado em História Contemporânea].

HABERMAS, J. (2002). Historia y Crítica de la opinión pública. La transformación estructural de la vida pública. Madrid: Ediciones G. Gili.

- (1997). L'Espace Publique. Archéologie de la Publicité comme dimension constitutive de la société bourgeoise. Paris : Payot.
KALIFA, D. (2001). La Culture de Masse en France - 1. 1860-1930. Paris: La Découverte.

- (2012) dir. La Civilisation du Journal. Histoire Culturelle et Littéraire de la Presse Française au XIXe Sciècle. Paris: Nouveau Monde.

LOUSADA, I. (2012). "Elos de progresso científico e social: contributo para a história das mulheres cientistas em Portugal". Women Science and Globalization: What's Up? Ed. Isabel Lousada e Maria José Gonçalves. Lisboa: Amonet, 2012, pp. 57-85. Disponível em http://run.unl.pt/bitstream/10362/8389/2/Amonet-Isabel\%20Lousada\%20p65.pdf

MELTON, J. (2001). The Rise of the Public in Enlightenment Europe. Cambridge: Cambridge University Press.

MIRANDA, P. C. M. (2002). As Origens $d a$ Imprensa de Massas em Portugal: o Diário de Notícias (1864-1889). Évora: Universidade de Évora [diss. Mestrado em Estudos Históricos Europeus].

PEIXINHO, A. T. (2013). "Cânone realista e discurso de imprensa". In: o Século do Romance. Realismo e Naturalismo na Ficção Oitocentista. Coimbra: CLP. 
QUEIRÓS, E. de (1970). Os Maias. Lisboa: Livros do Brasil [ $1^{\mathrm{a}}$ ed., 1888].

- (2009). Cartas Públicas. Edição Crítica de Ana Teresa Peixinho. Lisboa: Imprensa Nacional - Casa da Moeda.

SILVA, F. C. da (2002). Espaço público em Habermas. Lisboa : Imprensa de Ciências Sociais

SILVA, R. H. da (1996). "A arte sob a referência naturalista". In: António Reis (dir.). Portugal Contemporâneo. Vol. 1, Lisboa: Public. Alfa, pp. 689-696. 